\title{
Structural and optical analysis of Rhodamine B-dye mixed L/LB fi Im by Molecule combine model simulation
}

\section{ローダミンB色素/アラキジン酸混合 L・LB膜のシミュレーション物性解析}

\author{
Tsutomu TERAO and Sadao UEGUSA \\ Department of Electrical Engineering, Tokai University, 1117 Kitakaname, Hiratsuka, kanagawa, 259-1292, Japan \\ TEL : 81-0463-58-1211 (EXT. 4162) \\ Kenichiro NAKAMURA \\ Department of Optical Engineering, Tokai University, 1117 Kitakaname, Hiratsuka, kanagawa, 259-1292, Japan \\ TEL:81-0463-58-1211 \\ Takanobu KUMAMOTO \\ Department of Chemistry. Tokai University, 1117 Kitakaname, Hiratsuka, kanagawa, 259-1292, Japan \\ TEL : 81-0463-58-1211 \\ ( Received 25, November 1999 Accepted 13, April 2000) \\ The structure of a Rhodamine B-dye mixed L/LB fi Im was simulated at the molecular level. This study was carried \\ out for the aim of analyzing the molecule structure, the molecule occupation area and the optical absorption \\ spectra of L/LB film. As a result of the study for optical and electrical functions of L/LB film, it was shown \\ that there was an optimum point for the photo excitation of the thin film.
}

Keywords : Rhodamine B-dye mixed L/LB film, Molecule combine of model

\section{INTRODUCTION}

ローダミン B色素は $\mathrm{n}$ 型半導体の物性を示すことが知 られている。これを Langmuir-Blodgett (LB) 膜として製 膜する場合は、アラキジン酸分子と混合することで安定 に製膜できることが知られている。 ${ }^{1}$ 従来、LB 膜を応用 した研究が数多く行われているが、 ${ }^{2}$ その基礎的研究が 充分ではない。

本研究では、その基礎研究として LB 膜の物性解析のた め、モデルシミュレーションを用いて研究を行なった。 これまでのモデルシミュレーションの分子モデルは Fig.1(a) に示すように、 ${ }^{3}$ 棈円内に分子一つが入る大きさの楕円分子 モデルであった。その後 Fig.1(b)に示すような分子のアウトラ インをモデル化したものが作成されたが、 ${ }^{3}$ 実際の LB 分子
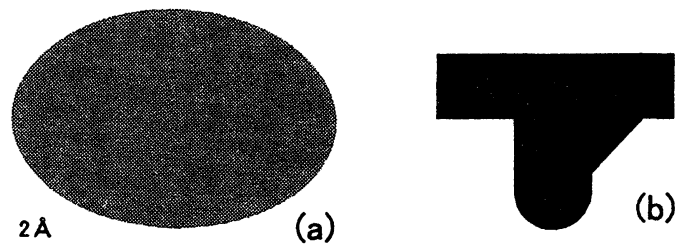

$$
\begin{aligned}
& { }_{\mathrm{C}}^{\mathrm{H}} \mathrm{C}_{\mathrm{N}}^{\mathrm{C}} \mathrm{C}^{-\mathrm{C}} \mathrm{C}-\mathrm{O} \mathrm{C}^{-\mathrm{C}} \mathrm{CH}_{\mathrm{CH}}^{\mathrm{C}} \\
& \text { H. } \mathrm{C}_{-\mathrm{C}}-\mathrm{C} \mathrm{C}^{-\mathrm{C}} \mathrm{CO}^{\mathrm{C}} \mathrm{C} \\
& 2 \mathrm{H} . \mathrm{C}^{-C} \mathrm{C}
\end{aligned}
$$

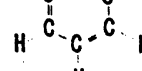

$$
\begin{aligned}
& \text { H }
\end{aligned}
$$

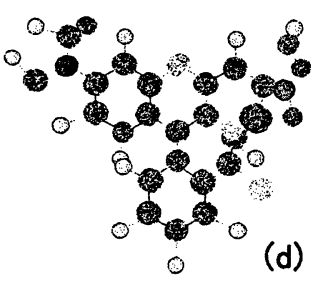

FIG. 1. Model of L/LB film mixed with Rhodamine B. (a) Elliptical model. (b) Realistic mol.model. (c) Molecular formula model, (d) M. C. model 1.
の微細挙動を理解するには充分でない。本報で作成した 分子結合モデルはFIG. 1 (d) に示すように、実際に水面に 浮かんだ分子平面状態のローダミン B 分子構造FIG. 1 (c) を考慮し正確にモデル化した。その分子結合モデルより L・LB 膜の分子集合状態を明確にし、分子状態とその色 素混合 L・LB 膜の光学物性との関係について解明するの が最終目的である。

\section{EXPERIMENTAL}

A. Stractural property analysis of L/LB film mixed with Rhodamine B-dye by molecule combine model simulation.

ローダミン B、アラキジン酸の分子構造は既に明らか であるが、 ${ }^{4} \mathrm{~L} \cdot \mathrm{LB}$ 膜としての分子構造の詳細は未知で ある。ここで、既知の両分子構造を Tablel に示す。同表 は、ローダミン B とアラキジン酸分子の化学式、L・LB

TABLE 1. Molecules for L/LB film.

\begin{tabular}{|c|c|c|}
\hline Pigment & Rhodamine $\mathrm{B}$ & Arachidic acid \\
\hline Molecule formula & $\mathrm{C}_{60} \mathrm{H}_{95} \mathrm{ClN}_{2} \mathrm{O}_{7}$ & $\mathrm{CH}_{3}\left(\mathrm{CH}_{2}\right)_{18} \mathrm{COOH}$ \\
\hline $\begin{array}{c}\text { Molecule formul a of } \\
\text { hydrophilic group }\end{array}$ & $\mathrm{C}_{20} \mathrm{H}_{6} \mathrm{ClO}_{3}$ & $\mathrm{C}_{2} \mathrm{O}_{2}$ \\
\hline Area $\left[\AA^{2}\right]$ & 57.1 & 16.5 \\
\hline
\end{tabular}
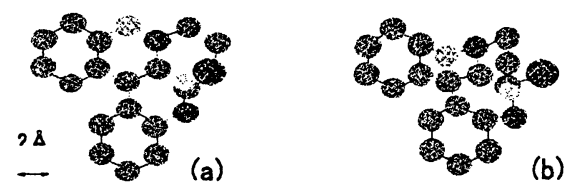

FIG. 2. Various models for Rhodamine $B$. (a) M. C. model 2, (b) M. C. model 3. 
膜として製膜される败の膜形成される親水基部分の化学 式、そして、各々単分子当たりの親水基部分の面積を示 す。これから以下の分子結合モデルを構成した。

前項 I で示したローダミン B 及びアラキジン酸の平面 分子構造を基準にし、Fig. 2 にFig. 1 (d)の基本分子構造 を変化させた二例を示す。すなわち、Fig.2(a) は、その 側鎖が折りたたまれたモデルである。そして同図(b)は単 結合部分の側鎖が外圧で折りたたまれ変形したと仮定し たモデルである。なお、アラキジン酸分子は、その親水 基のみが水面上に展開した状態をモデルとして採用した。 これら新規なモデルを「分子結合モデル」と称する。

このローダミンB とアラキジン酸の分子結合モデルを コンピューター上で、一定区画内にモル比 $\mathrm{Ma} / \mathrm{Mr}$ を所定 の量に変化させた混合分子モデルを各分子間の隙間が 最小になるように敷き詰めた。

これから水面上に分子が展開した場合の 1 分子当りの 平均分子占有面積 $(\mathrm{A})$ を求めた。

$B$. Characteristics analysis of L/LB film mixed with Rhodamine $B$ and dye.

アラキジン酸とローダミン B 色素のモル比 $(\mathrm{Ma} / \mathrm{Mr})=$

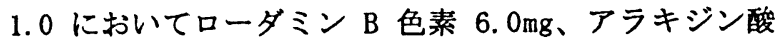
$1.9 \mathrm{mg}$ をクロロホルム $30 \mathrm{ml}$ に溶解する。 L・LB 装置(協和 界面化学株式会社製)のトラフ内の蒸留水面上にマイク ロシリンジにて、その混合溶液を $500 \mu 1$ 滴下し、装置を 作動さ膜圧一面積特性 (surface pressure - area curve) である $\pi-A$ 曲線を求める。

次に、LB 装置に同混合溶液を同量滴下し、11 層の LB 膜を作製する。この場合、膜圧を $20 、 25 、 28 、 30$ そして $35\left[\mathrm{mN} / \mathrm{cm}^{2}\right]$ と変化させた。製膜した LB 膜を吸光度测定器 (UV-2500PC 株式会社 SHIMADZU) で、吸光度スペクトルを測 定した。その結果とモデルシミュレーション結果ならび に $\pi$-A 曲線結果の三者間で膜物性を比較検討した。

\section{RESULT}

A. Structural analysis of L/LB film mixed Rhodamine $B$ and dye by molecule combine model simulation.

前記、分子結合モデル Molecule Combine (M. C. ) model 1, 2,3 で L 膜のシミュレーション化した状態を Fig. 3、 Fig. 4、Fig. 5 に示す。これらから 1 分子当りの平均分子 占有面積を算出し、かつ、膜圧 $30\left[\mathrm{mN} / \mathrm{cm}^{2}\right]$ における $\pi$ $\mathrm{A}$ 曲線から求めた平均分子占有面積值を Table2 に示す。

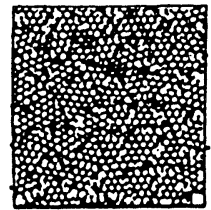

$M r: M a=1: 0.5$

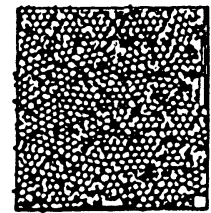

Mr:Ma $=1: 1.5$

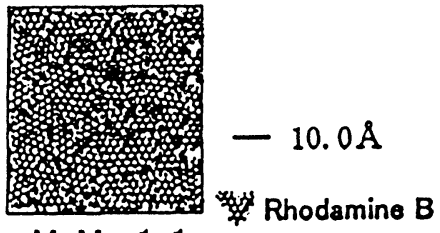

Mr:Ma=1: 1

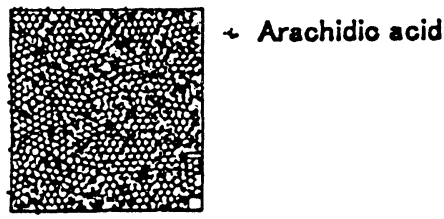

$M r: M a=1: 2$
FIG. 3. Simulation of the L/LB film by M. C. model 1.
これをグラフに表したのが Fig.6である。

Figure3 の状態は側鎖が通常状態のモデルである。本 データと実験值を比較した結果、誤差率 $50 \%$ と大きな誤 差が生じているのが明らかである。よって、分子形態と して本モデルより小さな分子結合モデルが必要となる。 そこでFig. 4 の側鎖が折りたたまれた,M.C. mode1 2 によ

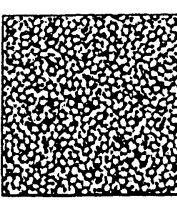

$M r . M a=1: 0.5$

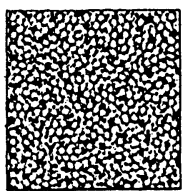

$M r . M a=1: 1.5$

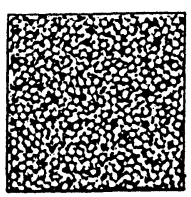

Mr.Ma $=1: 1$

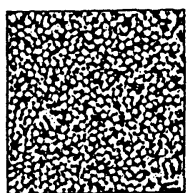

$M r: M a=1: 2$
$-10.0 \AA$

Rhodamine B

- Arachidic acid

FIG. 4. Simulation of the L/LB fi Im by M. C. model 2 .
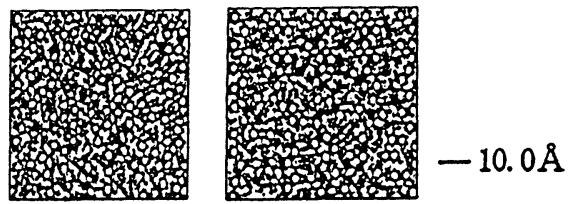

$M r: N_{a}=1: 0.5$

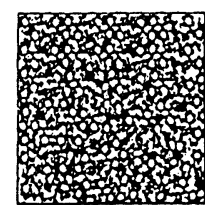

$M r: M z=1: 1.5$
Rhodamine B

+ Arachidic acid
FIG. 5. Simulation of the L/LB film by M. C. model 3 .

TABLE 2. Molecule occupation area of $L / L B$ film.

\begin{tabular}{|c|c|c|c|c|}
\hline \multirow{2}{*}{$\mathrm{Ma} / \mathrm{Mr}$} & \multicolumn{4}{|c|}{ Molecule occupation area $(A)\left[\mathrm{A}^{2}\right]$} \\
\cline { 2 - 5 } & M. C. model1 & M. C. mode/2 & M. C. model3 & Real film \\
\hline 0.5 & 74.0 & 40.9 & 35.8 & 52 \\
\hline 1.0 & 57.2 & 32.0 & 28.7 & 29 \\
\hline 1.5 & 47.3 & 26.6 & 23.1 & 23 \\
\hline 2.0 & 41.9 & 24.0 & 20.4 & 19 \\
\hline
\end{tabular}

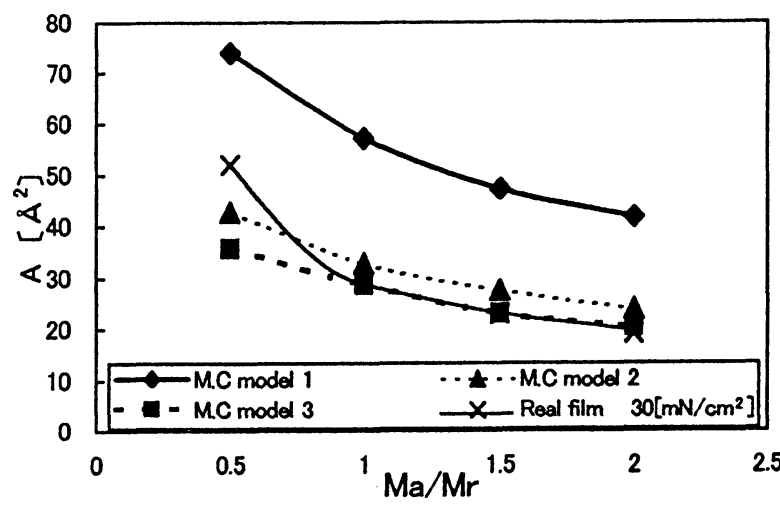

FIG. 6. Relation between Arachidic acid/ Rhodamine B and molecule area. 
る平均分子占有面積と実験値の比較を行った。しかし、 25\%以上の誤差が生じている。そこでさらにFig. 5 に示 す分子の単結合部分を変形させて分子内部に圧縮した M. C. mode1 3 により比較した。その結果、Table2 と Fig. 6 に示すように、前記 2 モデルと異なり、モル比 1、1.5、 2 で実験值と同一の值を得ることができた。

しかし、モル比 0.5 では、いぜん大きな誤差が生じて いる。この原因は、平面積の小さいアラキジン酸分子は ローダミン B 分子の間に入り、ローダミン B 分子の㻋水 基がぶつかり合うのをふせぐが、モル比 0.5 ではアラキ ジン酸含有量が少ないため瑓水基がぶつかり合い本モデ ルのような密着した分子構造を取ることが困難であった と考えられる。

この結果、作成した分子結合モデルのうち、M.C. mode1 3 の構造が実験值を良く説明することから、集合分子に 大きな膜圧が加えられると、分子の平面形状が変化する と結論された。

ここで、実際の色素混合 L・LB 膜分子配列がどのよう な状態にあるのか判断が難しいので $\mathrm{Ma} / \mathrm{Mr}=1.0$ の場合 をシミュレーション上で、分子配列の整列状態と乱雑状 態の比較をした。モデルシミュレーション例を Fig. 7、 それらの平均分子占有面㮩と誤差を Table3 に示す。また、 そのグラフをFig. 8 に表す。

Table3 と Fig. 8 より各々分子結合モデルの整列・乱雑 状態の平均分子占有面積の比較では、誤差率が $7 \%$ 以内 と小さく、両者の有意差は認め難い。この結果は、これ まで色素混合 L・LB 膜の分子配列は整列状態にあると暗 に考えられてきたが、本結果は乱雑状態の配列の可能性 のあることを立証している。

$B$. Relationship between structural and optical property of L/LB film mixed with Rhodamine B-dye.

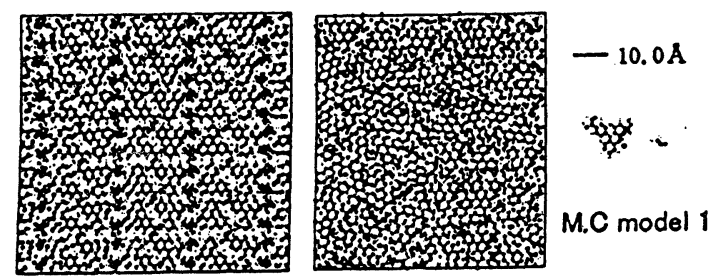

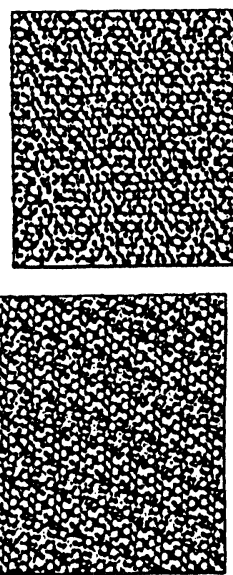

Order

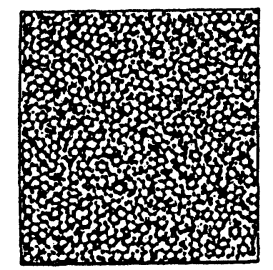

$$
-10.0 \AA
$$

\&

M.C model 2

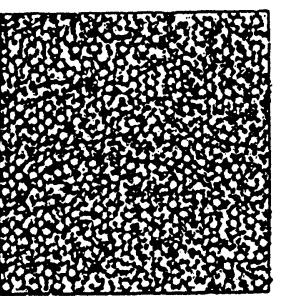

$-10.0 \AA$

ats

MC model 3

\section{Disorder}

FIG. 7. Simulation models of order and disorder molecule arrangement.
実際の L・LB 膜の分子状態を知るために Table4 の条件 で $\pi$ - A 曲線を測定した。また L・LB 膜の電子機能性の 測定として、同条件下での $\pi-A$ 特性と吸光度分布特性

TABLE 3. Character of order or disorder state.

\begin{tabular}{|c|c|c|c|}
\hline \multirow{2}{*}{$\begin{array}{l}\text { Model } \\
\text { type }\end{array}$} & \multicolumn{2}{|c|}{ Molecule occupation area $\left[\AA^{2}\right]$} & \multirow[b]{2}{*}{ Error $[\%]$} \\
\hline & Order & Disorder & \\
\hline $\begin{array}{c}\text { M. C. } \\
\text { model } 1\end{array}$ & 53.3 & 57.2 & 6.7 \\
\hline $\begin{array}{c}\text { M. C. } \\
\text { model } 2\end{array}$ & 31.3 & 32 & 2. 2 \\
\hline $\begin{array}{c}\text { M. C. } \\
\text { model } 3\end{array}$ & 27.1 & 28.7 & 5.4 \\
\hline
\end{tabular}

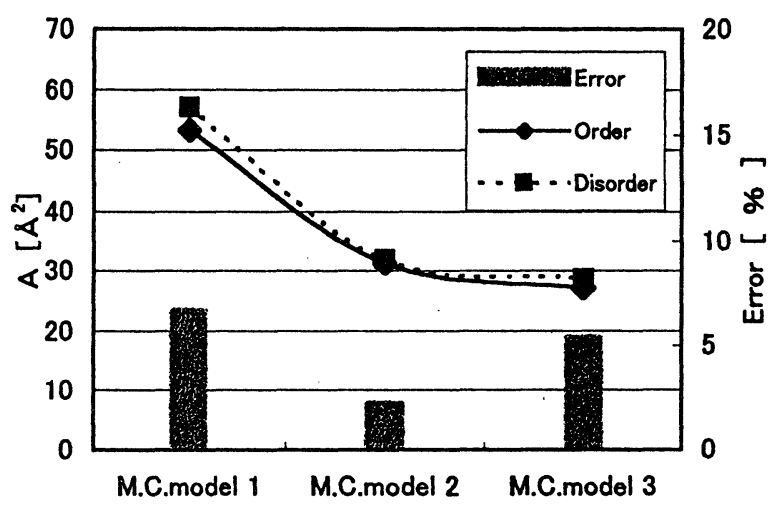

FIG. 8. Molecule area and error by various models.

TABLE 4. Condition for $\pi-A$ experiment.

\begin{tabular}{|c|c|}
\hline Kind & Parameter \\
\hline Rhodamine B-dye mixed L/LB fi Im \\
\hline Ma : Mr & $1: 1$ \\
\hline \multicolumn{2}{|c|}{ A material noun } \\
\hline Rhodamine B & $6[\mathrm{mg}]$ \\
\hline Arachidic acid & $1.9[\mathrm{mg}]$ \\
\hline \multicolumn{2}{|c|}{ Dissolve } \\
\hline Chloroform & $30[\mathrm{ml}]$ \\
\hline \multicolumn{2}{|c|}{ LB } \\
\hline Barrier speed & $20\left[\mathrm{~cm}^{2} / \mathrm{min}\right]$ \\
\hline The transfer range & $965 \sim 195\left[\mathrm{~cm}^{2}\right]$ \\
\hline The water temperature & $26\left[{ }^{\circ} \mathrm{C}\right]$ \\
\hline
\end{tabular}

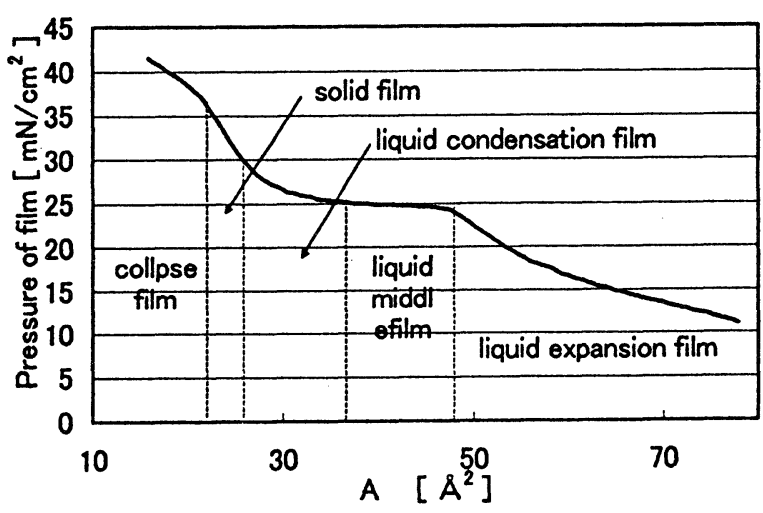

FIG. 9. $\pi-A$ curve. 


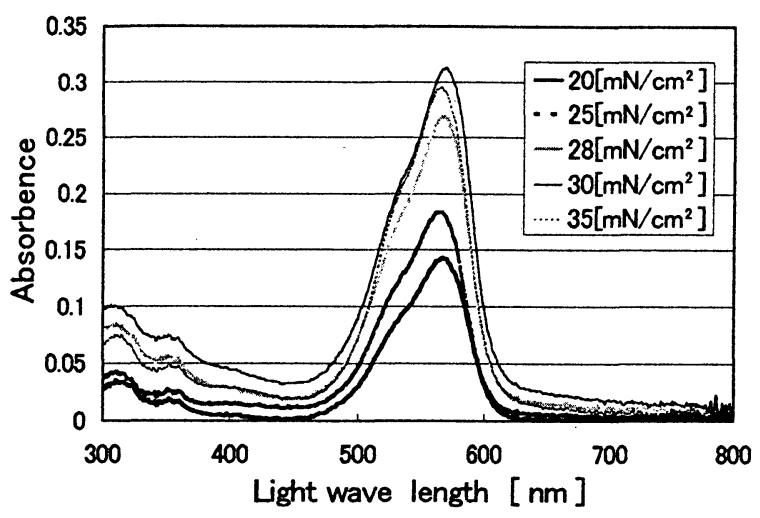

FIG. 10. Optical absorption spectra of LB films mixed with Rhodamine $B$ at different film pressures.

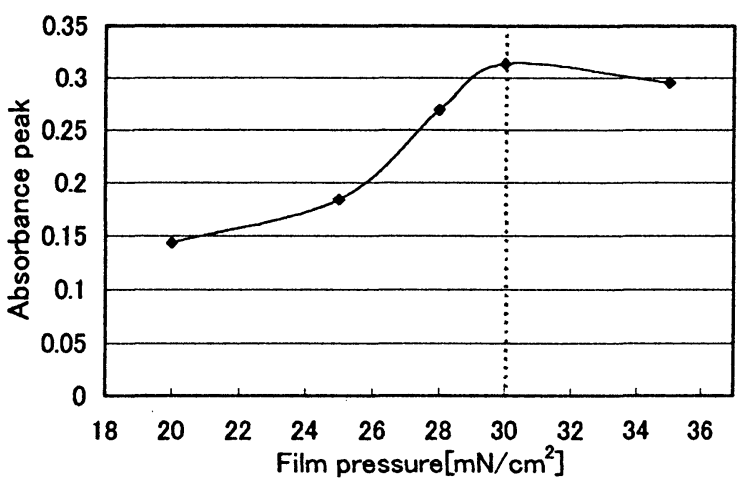

FIG. 11. Film pressure dependence of absorbance peak intensities.

を膜圧 $=20 、 25 、 28 、 30 、 35\left[\mathrm{mN} / \mathrm{cm}^{2}\right]$ と変化させ測定 した。その結果を Fig. 9、Fig. 10 に示し、考察を行っ た。Figure 9 より膜圧 $24\left[\mathrm{mN} / \mathrm{cm}^{2}\right]$ 以下が液体膨張膜、 $25\left[\mathrm{mN} / \mathrm{cm}^{2}\right]$ が中間膜、26 から $30\left[\mathrm{mN} / \mathrm{cm}^{2}\right]$ が液体凝縮 膜、 $30\left[\mathrm{mN} / \mathrm{cm}^{2}\right]$ 以上が固体膜となる。膜圧 $35\left[\mathrm{mN} / \mathrm{cm}^{2}\right]$ 以上で $L \cdot L B$ 膜は崩壊している。気体膜は、本 $\pi-A$ 曲 線では認められなかった。

Figure10 からローダミンB色素混合 L・LB 膜は、い ずれの膜でも光波長 $560[\mathrm{~nm}]$ で吸光度ピークが現れる。 各々の吸光度ピークと膜圧の関係をグラフ Fig. 11 に示 す。Figure11 では、膜圧 $30\left[\mathrm{mN} / \mathrm{cm}^{2}\right]$ において曲線上 にピークが現れる。膜圧 $35\left[\mathrm{mN} / \mathrm{cm}^{2}\right]$ では低下してい る。これより本研究でローダミン B 色素混合 L・LB 膜の 電子機能性が最も優れた状態は、液体膜から固体膜への 変化点である膜圧 $30\left[\mathrm{mN} / \mathrm{cm}^{2}\right]$ であることを確認した。
ここで、Fig. 9 の $\pi$-A曲線と（i ）のモデルシュミレ 一ションの平均分子占有面積結果を比較する。前述でも 述べた通り、膜圧の変化で膜の平面分子構造は変わる。 平均分子占有面積約 $50\left[\AA^{2}\right]$ 以下で液体膨張膜、30 から $50\left[\AA^{2}\right]$ で液体膜、 $30\left[\AA^{2}\right]$ 以下が固体膜に相当すると 考えられる。これを、分子結合モデルにあてはめてみる 之、M.C. mode1 1 は液体膨張膜、M. C. mode 12 は液体膜、 M. C. mode1 3 は固体膜での分子モデルに相当する。M.C. model 3 は、吸光度分布より光電子機能性が最も優れて いる膜圧 $30\left[\mathrm{mN} / \mathrm{cm}^{2}\right]$ のモデルである。

電子機能性と分子混合モル比の関係では、 $\mathrm{Ma} / \mathrm{Mr}=1$ で安定な製膜が可能であり、光特性においても最も優れ た膜であることが確認された。

\section{CONCLUSION}

1) 本研究で作成した分子結合モデルは、分子構造と L・ LB 膜物性の因果関係を追及していく上で有効な知見 が得られた。

2)これまで、実際の L・LB 膜とその理論との間に大きな 相違が生じていた。これはこの分野の研究者の固定観 念による「分子の型は変化しないりという前提概念が大 きな原因であった。しかし本研究結果から今後、「L・ LB 膜の応用」の分野で、本知見が応用されると考えら れる。

3)L・LB 膜の分子配列が整列ばかりでなく、乱雑配列で あるという可能性を見出した。

4）ローダミン B 色素混合 L・LB 膜の混合モル比 (Ma/Mr) が 1、膜圧 $30\left[\mathrm{mN} / \mathrm{cm}^{2}\right]$ で、最も優れた光電子穖能性 を示すことを確認した。

\section{REFERENCES}

${ }^{1} \mathrm{H}$. Kuhun D. Mobius and H. Bucher, rTechniques of Chemistry」, EMI no. 113 (1973), p25.

${ }^{2}$ Tosifumi I shi i. TThe photo-rechargeable battery with merocyanine dye mixed LB film」, graduation thes is (1998).

${ }^{3} \mathrm{~K}$. Nakamura and Y. Nakaz ima, Comparion of the propety of mixed LB film . graduation thesis (1997).

${ }^{4} \mathrm{~K}$. Iriyama, rAn organic super-pale film」, houkabou (1992), p6

${ }^{5}$ M. Komi yama M. Watanabe and Y Ookawa, TLB film J touzyusya, (1990).

Presented at ' 99 SAS Intelligent Symposium 